\title{
Pore Size and Permeability of Experimentally Compacted Smectire and Kaolinite Clay.
} Permeability and Elastic Moduli

\section{Fabricius, Ida Lykke}

Published in:

Proceedings of Third EAGE Shale Workshop Shale Physics and Shale Chemistry

Publication date:

2012

Document Version

Publisher's PDF, also known as Version of record

Link back to DTU Orbit

Citation (APA):

Fabricius, I. L. (2012). Pore Size and Permeability of Experimentally Compacted Smectire and Kaolinite Clay. Permeability and Elastic Moduli. In Proceedings of Third EAGE Shale Workshop Shale Physics and Shale Chemistry

\section{General rights}

Copyright and moral rights for the publications made accessible in the public portal are retained by the authors and/or other copyright owners and it is a condition of accessing publications that users recognise and abide by the legal requirements associated with these rights.

- Users may download and print one copy of any publication from the public portal for the purpose of private study or research.

- You may not further distribute the material or use it for any profit-making activity or commercial gain

- You may freely distribute the URL identifying the publication in the public portal 


\title{
C03 Pore Size and Permeability of Experimentally Compacted Smectire and Kaolinite Clay. Permeability and Elastic Moduli
}

\author{
I.L. Fabricius (Technical University of Denmark)
}

\section{Introduction}

Clay and shale sequences may constitute thick intervals with a gradual decrease in porosity and corresponding increase in velocity of elastic waves. This is seen also in intervals where clay and shale samples easily disintegrate in water, which would indicate that the porosity reduction is merely a consequence of mechanical compaction. Mondol et al. (2007, 2008) studied this phenomenon by laboratory experiments involving compaction of dry or sea-water saturated smectite and kaolonite powder. During these tests, velocity of elastic compressional waves and of elastic shear waves was measured; the volume of expelled water was monitored, and porosity $(\phi)$ as well as bulk density, $\rho$, could be calculated. From these data the authors could derive compressional modulus (M), shear modulus $(\mathrm{G})$, and bulk modulus $(\mathrm{K})$ as well as fluid permeability (k). From samples of the kaolinite and smectite used during these experiments, the specific surface could be measured by nitrogen adsorption (BET, Fabricius 2011). The BET data allow calculation of average pore radius. The present study addresses whether these data may be applied to derive a tool for estimating permeability from elastic moduli, bearing in mind that elastic moduli may be derived from logging data.

\section{Elastic moduli}
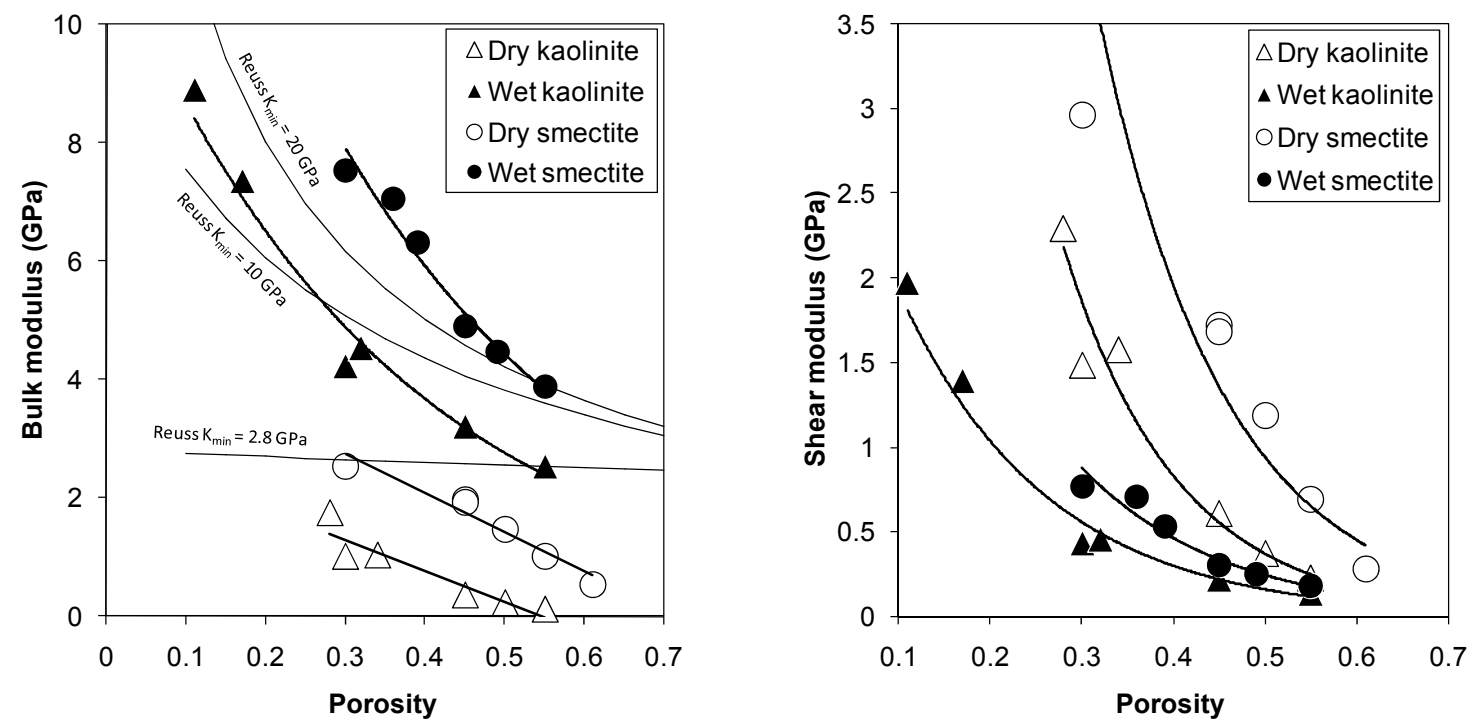

Figure 1 Elastic moduli of dry and sea-water saturated clay powders versus porosity. Experimental data from Mondol et al. (2007). Moduli were derived from bulk density, $P$-wave velocity $\left(v_{P}\right)$ and shear wave velocity $\left(v_{S}\right)$ of elastic waves: $M=v_{P}^{2} \rho$; $G=v_{S}^{2} \rho ; K=M-4 G / 3$. Reuss (1929) lower bounds for mixtures of two components is calculated as: $1 / K=\phi / K_{f l}+(1-\phi) / K_{\min }$, where $K_{f l}$ is bulk modulus of pore fluid, and $K_{\min }$ is bulk modulus of the mineral phase.

Elastic bulk modulus and shear modulus of dry and water saturated kaolinite and smectite are plotted versus porosity in Figure 1. For porosity above 50\%, dry kaolinite has bulk modulus close to zero in accordance with a Reuss mixture of air and particles, and correspondingly, water saturated kaolinite with porosity above $50 \%$ has a bulk modulus equivalent to a Reuss mixture of water and a mineral with a bulk modulus of $2.8 \mathrm{GPa}$. By contrast, for high-porosity smectite, bulk and shear moduli are 
relatively high and would not match a Reuss model. As porosity decreases moduli increase, and for each mineral, shear modulus are significantly higher in the dry state than in the water saturated state.

The departure from a Reuss model for elastic moduli with declining porosity would indicate improved particle contact caused by the added stress, and if elastic moduli are compared to effective stress (Figure 2), we find that bulk modulus for the water saturated state increases with increasing effective stress on two close trends, where tests with kaolinite tend to give higher modulus. In the dry state, bulk moduli for tests with smectite tend to give higher values than tests with kaolinite, but both data
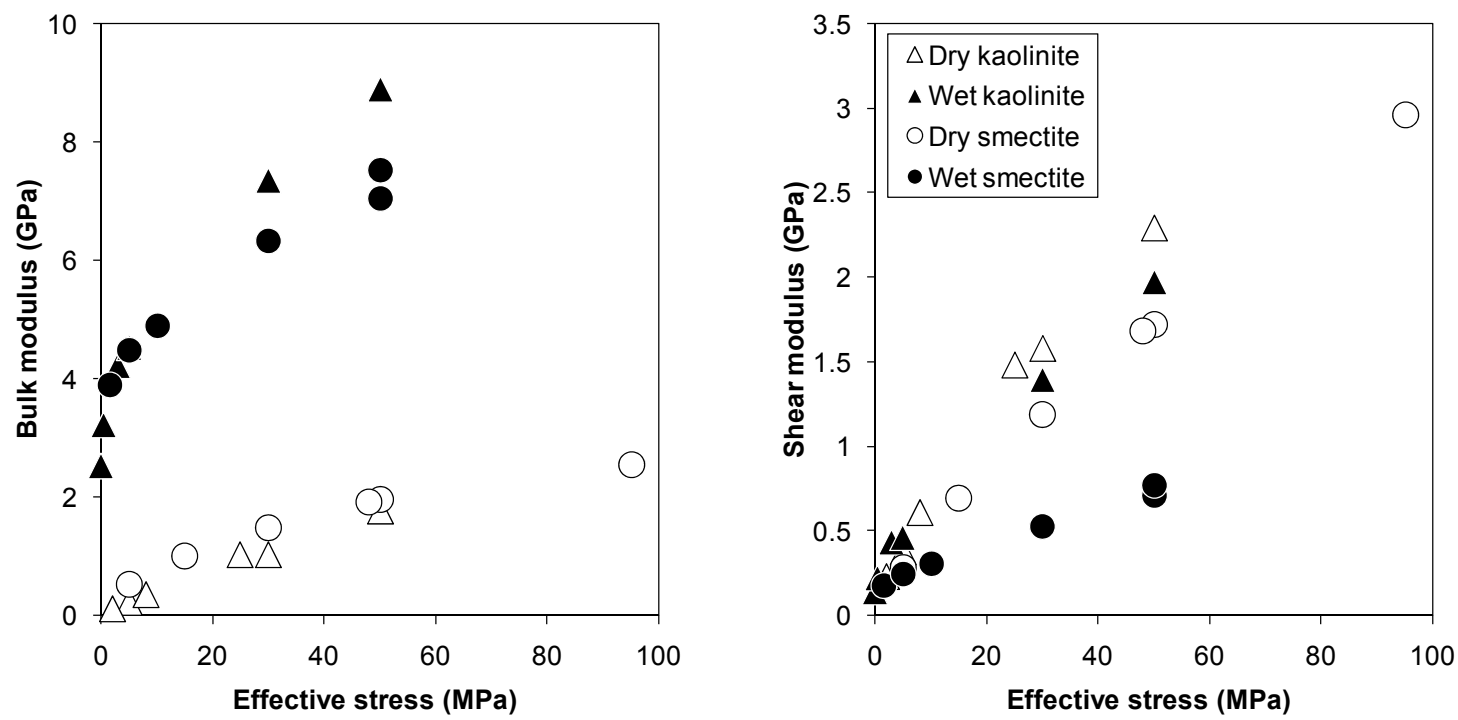

Figure 2 The same data as in Figure 1 plotted versus vertical effective stress. The effective stress, $\sigma$,' was calculated from total vertical stress, $\sigma$, and fluid pressure, $U$, according to Terzaghis law: $\sigma^{\prime}=\sigma-U$.
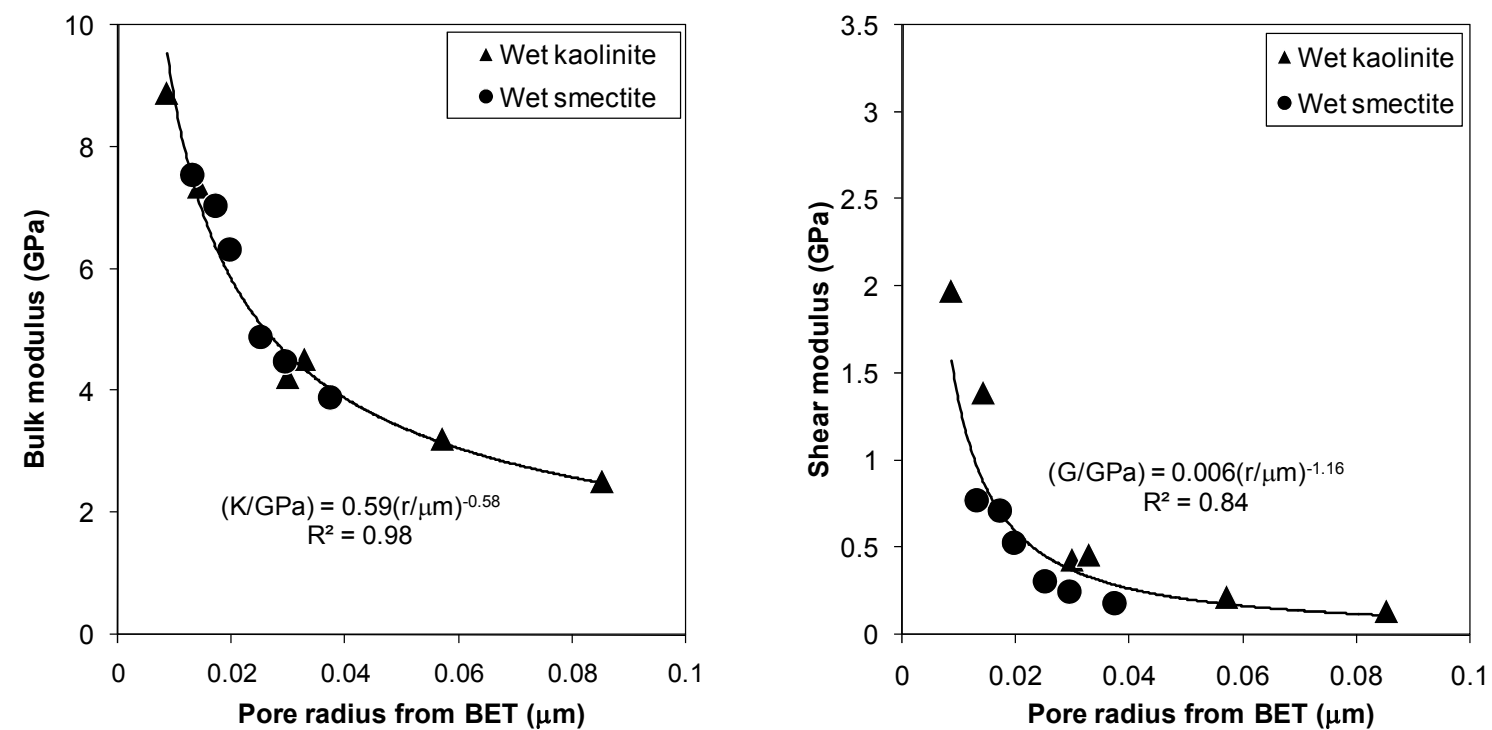

Figure 3 The sea water saturated data from Figure 1 and 2 plotted versus pore radius, $r$, as calculated from porosity, grain density, $\rho_{g}$, and specific surface, $S_{B E T}$ : $r=2 \phi /\left(S_{B E T} \rho_{g}(1-\phi)\right)$. 
sets follow smooth positive trends. For shear modulus, dry as well as water saturated, kaolinitic tests follow the same positive trend, possibly shared by the dry smectitic tests; whereas water saturated smectitic tests follow a trend of lower shear modulus for a given effective stress.

If we focus on the water saturated state, we find that if mineralogy is unknown, bulk modus is best predicted from effective stress, whereas shear modulus is best predicted from porosity. For both moduli, trends versus porosity and effective stress are distinct for the two minerals. In order to normalize for the mineralogical effect, the difference in grain size between the two tested minerals should be taken into account. This can be done by calculating the equivalent pore radius, $r$, from specific surface $\left(\mathrm{S}_{\mathrm{BET}}\right)$ and porosity. When elastic moduli are plotted versus pore radius, bulk modulus

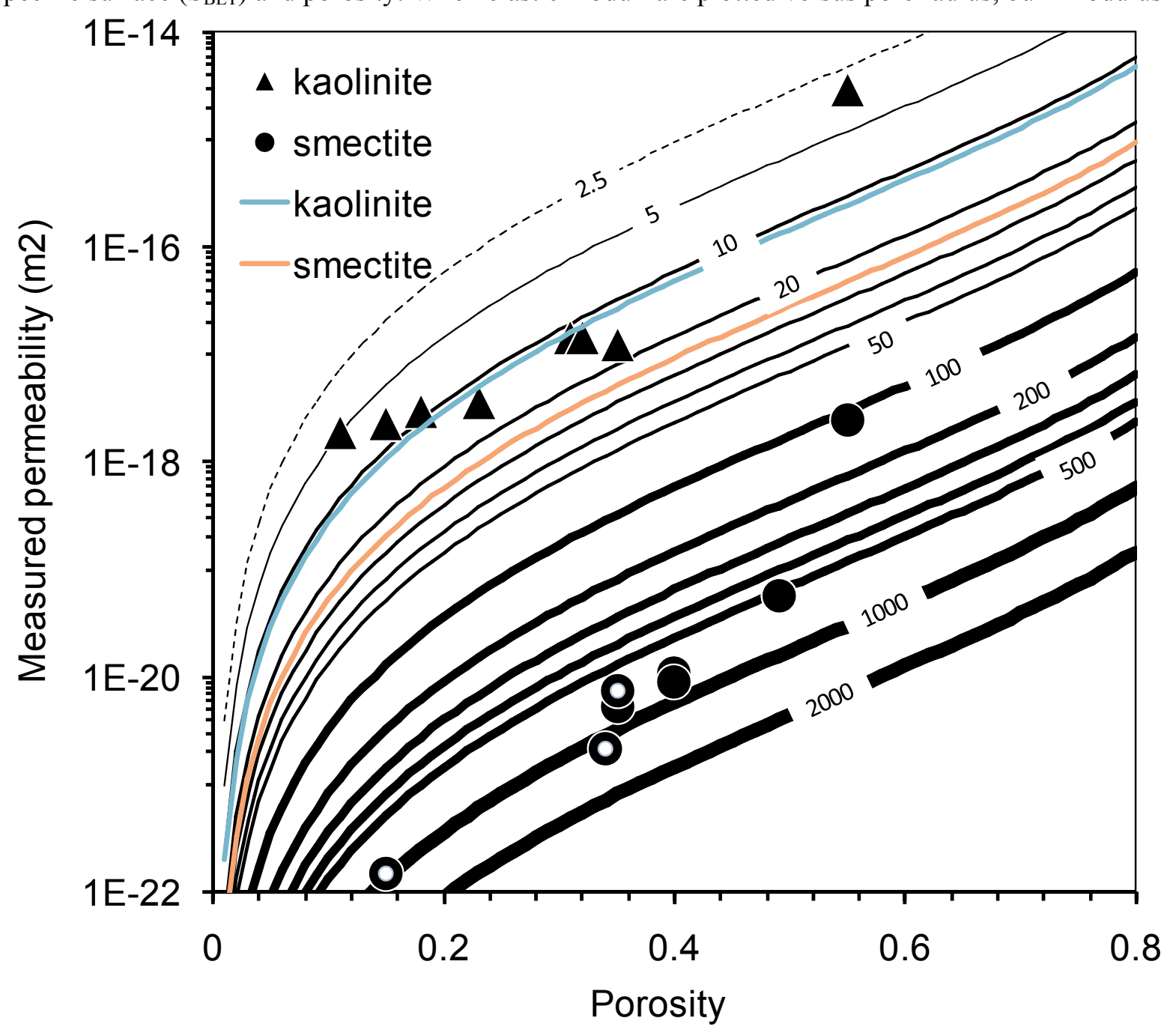

Figure 4 Permeability and porosity data as measured by Mondol et al. (2008). Curves in the upper figure represents constant $S_{B E T}$ as calculated by using Kozeny's equation: $k=c \phi^{3} /\left(S_{B E T} r_{g}(1-\right.$ $\phi))^{2}$ (Mortensen et al. 1998). The factor c may be estimated from porosity. In the studied interval it ranges between 0.2 for the lowest porosity to 0.26 for the highest porosity (Mortensen et al. 1998). Data points with white dots are not measured but estimated by Mondol et al. (2008).

follows a common trend, whereas smectitic tests tend to give lower shear moduli than kaolinitic tests. A less well defined common trend may be defined though, also for shear modulus (Figure 3). 


\section{Permeability}

A relationship between pore radius and elastic modulus for compacted clay would open the possibility of predicting permeability of clay and soft shale from elastic modulus data. In order to test this possibility, measured permeability data were plotted against porosity and compared to lines of equal specific surface as calculated from Kozeny's equation in the formulation of Mortensen et al. (1998) (Figure 4). We find that tests with kaolinite plots on a trend very close to the measured BET, whereas smectitic tests fall on higher BET than the measured and on a trend of increasing BET with declining porosity. It should be borne in mind that the permeabilities for smectitic tests range from $10^{-18} \mathrm{~m}^{2}$ to $10^{-22} \mathrm{~m}^{2}(1 \mu \mathrm{D}-0.1 \mathrm{nD})$ and are difficult to measure, some of the data reported by Mondol et al. (2008) are for this reason estimated from trends. The possibility remains that in this low permeability range, permeability modeled from porosity and BET is more reliable than measured data.

\section{Conclusions}

Elastic moduli of compacted clay may be primarily controlled by pore fluid and pore radius.

If this holds true, it should be possible to predict permeability of theses sediments from elastic moduli as derived from density and sonic logs in combination with porosity from neutron-porosity and density logs.

\section{References}

Fabricius, I. L. [2011] Relationship between elastic moduli and pore radius in clay aggregates. In: Unconventional ressources and the role of technology: 73rd EAGE Conferenc \& exhibition, Vienna 23-26 May 2011; Conference proceedings \& exhibitors' catalogue. CD-ROM.

Mondol, N.H., Bjørlykke, K., Jahren, J. and Høeg, K. [2007] Experimental mechanical compaction of clay mineral aggregates - Changes in physical properties of mudstone during burial. Marine and Petroleum Geology, 24, 289-311.

Mondol, N.H., Bjørlykke, K., and Jahren, J. [2008] Experimental compaction of clays: relationship between permeability and petrophysical properties in mudstones. Petroleum Geoscience, 14, 319337.

Mortensen, J., Engstrøm, F., and Lind, I. [1998] The relation among porosity, permeability, and specific surface of chalk from the Gorm field, Danish North Sea, SPE 31062, SPE Reservoir Evaluation \& Engineering, 1, 245-251.

Reuss, A. [1929] Berechnung der Fliessgrenze von Mischkristallen auf Grund der Plastizitätsbedingungen für Einkristalle. Zeitschrift für Angewandte Mathematik und Mechanik, 9, 49-58. 